\title{
Intercultural Competence at the Intersection of Engineering and Study Abroad
}

\section{Dr. Deborah Besser P.E., University of St. Thomas}

Dr. Besser, holds a MS and BS in civil engineering, and $\mathrm{PhD}$ in education. Currently, she is the director of University of St. Thomas Center for Engineering Education; and she teaches engineering education and engineering courses. Previous experience includes faculty positions in diverse universities where she has taught a variety of coursework ranging from engineering education to structural systems to engineering economy. Prior to teaching, Dr. Besser, a licensed engineer, was a design engineer with HNTB-CA, where she worked on seismic retrofits and new design of high profile transportation structures.

\section{Dr. Camille M. George, University of St. Thomas}

Camille M. George is the Associate Dean of Engineering and an Associate Professor of Mechanical Engineering at the University of St. Thomas in St. Paul, MN (USA). Camille George has two Bachelor's degrees, one in Liberal Arts from the University of Chicago, and one in Fluids Engineering from the University of Illinois at Chicago; a M.S. and a Ph.D in Mechanical Engineering from the University of Illinois at Chicago and the University of Minnesota, respectively. Currently, she is interested in global sustainability and engineering for the developing world. Dr. George has worked on projects in the Caribbean and in West Africa. Her projects combine her expertise in thermodynamics and heat transfer with the preservation of food, the cooling of space in hot dry climates, and empowering women's cooperatives to better manage their natural resources.

\section{Ms. Erin Anne Kern, University of St. Thomas}

Erin is a Mechanical Engineering and French student at the University of St. Thomas in her junior year of study. She works in the Playful Learning Lab in the engineering department of her university and leads projects on using code to interpret music. Erin is interested in technical writing, finding ways to connect art and engineering, and sustainable engineering, and she is also significantly involved in the Department of Residence Life on campus.

\section{Jenna Laleman, University of St. Thomas}

Jenna is in her third year of studies at the University of St. Thomas, majoring in Elementary Education and STEM Education with a minor in Psychology. She works at her university's Playful Learning Lab which focuses on engaging students of all ages in hands-on, innovative engineering education, especially focusing on reaching the underrepresented within the STEM fields. Jenna is working on a variety of STEM student outreach programs including leading the University's STEPS (Science, Technology, and Engineering Preview Summer) Camp, developing the curriculum, leading the staff, and working as the primary researcher. 


\title{
Intercultural Competence at the Intersection of
}

\author{
Engineering and Study Abroad
}

\begin{abstract}
Study abroad participation has exploded in higher education institutions with the percent of students in the United States who study abroad rising by just over five percent in a single academic year (NAFSA, 2016). American students majoring in STEM (Science, Technology, Engineering, and Math) fields represent the largest proportion of students studying abroad at nearly 23 percent (IIE, 2016). As popularity for study abroad programs has grown, the evidence for study abroad success has been questioned. Previous success metrics of study abroad programs focused on the number of students participating and students' self-reports of being "transformed". Today's metrics require successful study abroad programs to demonstrate students' development of intercultural agility and competence (Vande Berg et al, 2012). Intercultural knowledge and competence is "a set of cognitive, affective, and behavioral skills and characteristics that support effective and appropriate interaction in a variety of cultural contexts" (Bennett, 2008).
\end{abstract}

As civil engineering graduates increasingly participate in the international engineering work force, competencies outlined in the Civil Engineering Body of Knowledge for the $21^{\text {st }}$ Century (ASCE, 2008), such as globalization (analyzing engineering works and services in order to function at a basic level in a global context) and ABET Student Outcomes (ABET, 2014) requiring students to understand the impact of engineering solutions in a global, economic, environmental and societal context, may be significantly optimized by study abroad experiences.

How courses are structured is key to providing intercultural knowledge and competence. An engineering instructor's experience creating courses balancing intercultural knowledge and engineering content has only recently entered the body of knowledge on intercultural learning. This paper explores an engineering study abroad course as a case study in furthering the discussion. The research approach taken involves mixed methods with a nod to quantitative cultural competence measures and qualitative hermeneutic phenomenology, with qualitative results to follow. To delve into understanding the experience of the study abroad engineering student, the research question explored is, "To what extent may a short-term study abroad engineering course influence student intercultural competence?"

\section{Context}

This paper outlines the revision of a short-term study abroad engineering course. Previously, the existing course had been offered on alternate years for seven separate offerings, when two new components were added to the content: 1 . Transfer of engineering content in a new context, specifically basic engineering mechanics analysis, with a nod to structural analysis, and 2 . Intercultural knowledge and competence. The evolution of the course content reflects the need 
for continuous improvement in engineering content, as well as, a growing body of literature which points to the need for instructor led intercultural intervention for intercultural knowledge and competence growth. This paper focuses on the integration of intercultural competence in the context of developing future engineers who have both the skill set and mindset to understand engineering projects and services within a "global context". Central to this goal is a baseline understanding of intercultural learning theory which is briefly delineated from a theoretical perspective. The course is then examined as a case study. And finally, assessment of student learning growth is considered in terms of quantitative instruments; qualitative analysis, which is currently in progress, will be reported at a later date. The paper culminates in a discussion of the implications of this work in progress.

\section{Intercultural Knowledge and Competence}

In an increasingly interconnected global market place, intercultural knowledge is a basic competency which is advantageous to the employee, employer and global citizen. Higher education has addressed intercultural development through multiple measures, including the increased growth in the number of study abroad programs and, increasingly, through the quality of program offerings. Study abroad growth has occurred in both international students studying in the US and US students who elect to study abroad. The Institute of International Education reports that over one million international students studied at US higher education institution in 2015-2016. This represents 5 percent of the US higher education student population; over one third of international students studied engineering, math or computer science. A smaller number of US students, 313,000, studied abroad in 2015-2016 and approximately a quarter of these students majored in STEM fields (IIE, 2016). How US students experience, process, and internalize their study abroad experience, the resulting growth in intercultural development, and the US educator's role in student development is the focus of this study.

As US student study abroad opportunities have grown in number, so too has the pool of students who self-report that their study abroad experience has been a transformative experience (Vande Berg et al, 2012). Yet, these allegations of "transformation" may not hold up under critical analysis. Research into the transformative component of study abroad experiences has yielded interesting lessons, in how students develop, or in the case of early reports, fail to develop. Vande Berg et al (2012) lay out three shortcomings of relying on student self-reports of transformative growth including, first, the folly in relying on students' self-reports to assess student learning. Clearly, self-reports in other domains, including engineering, is not an acceptable objective measure of growth. Second, students, on average, may not have the developmental theoretical back ground needed to assess growth. Third, the financial investment and time investment required for a study abroad experience may elicit student "social desirability bias"; that is, the student is mirroring the enthusiasm exhibited by peers, staff, faculty and family as part of the study abroad experience.

If intercultural learning may not be accurately reflected in student self-reports, then what is intercultural learning? Bennett defines intercultural learning as the acquisition of transferable intercultural competence; that is competence that can be applied to dealing with another culture (Bennett in Vande Berg et al., 2012). Hammer further defines cultural adaption as "the capability 
of shifting perspective to another culture and adopting behavior according to cultural context" (Hammer, 2008). Vande Berg codifies intercultural competencies which faculty, as cultural coaches, can help students learn by:

- helping students increase their cultural and personal self-awareness through reflection on their own experiences;

- helping students increase their awareness of others' ways of making meaning and behaving in various contexts;

- helping students bridge cultural gaps, that is helping students shift perspectives and adapt behavior to other cultural contexts (Vande Berg et al., 2012).

In terms of shifts in teaching intercultural knowledge, drawn from the evolution of education in general, the instructor was mindful of the epistemological stance taken, specifically the existing undertones of positivism and relativism which the course was seemingly based upon and the expansion of course modules based on constructivist modules. The positivist stance asserts learning is based on experience and the physical environment. This narrative assumes that some human societies are advanced, "these are the privileged places students will be sent and that most of them are located in Western Europe" (Bennett in Vande Berg et al., 2012). The relativist paradigm assumes that all cultures are equal and that immersion in a new and different environment is a requisite for learning. This paradigm emphasizes the naturally occurring learning that occurs when students spend time engaged with the host culture. Conversely, the constructivist paradigm emphasizes learning through immersion and cultural mentoring. The goal of this paradigm is "to allow students to learn to shift cultural perspectives and to adapt their behavior to other cultural contexts" (Bennett in Vande Berg et al., 2012). As universities incorporate intercultural learning into mission statements with resources to support intercultural learning in students, more study abroad programs are evolving their cultural mentoring training programs. In fact, the constructivist paradigm is dependent on trained educators intervening in student learning.

A further delineation of culture which is helpful in considering the instructor's role in the learning process, is the difference between objective culture and subjective culture. Bennett (2013) points to Berger and Luckmann's (2011) constructivist's definition of "culture" which includes a delineation between "objective culture" and "subjective culture". Objective culture, Bennett's "Big-C" culture, encompasses institutional components including systems, such as political systems and economic systems, products, including art, music, cuisine, literature, and architecture. Big-C culture has been the focus of traditional education. Objective culture also includes the historical development of society's institutions. Conversely, subjective culture, Bennett's "little-c" culture, encompasses the "experience of the social reality formed by a society's institutions, otherwise stated as the "worldview of a society's people." Within the subjective, "little-c" culture, a society generates a way to categorize phenomena, to organize and coordinate communication and to assign value to ways of being including social mores. "So, for instance, North Americans have a less abstract worldview than do Northern Europeans, which leads North Americans to more easily coordinate themselves tactically around the processes (how to get it done) rather than strategically around ideas (why to do it). It also inclines members of each group to value their own perceptual organization as superior, so that North Americans are generally pleased with themselves for being practical problem solvers and relatively impatient with extended theoretical consideration. Northern Europeans, on the other hand, tend 
to evaluate American decision making negatively as "shooting from the hip" (Bennett, 2013). Objective culture is internalized through socialization and subjective culture is externalized through role behavior." (Bennett, 2013). For this offering of the course, the course experiences still included objective Italian culture, but also added was subjective culture development and reflection. Course modules focused on the full spectrum of culture, so that students were better able to articulate subjective and objective components of culture.

How instructors and students develop cultural learning is considered through stage development theory. Seemingly, every developmental theorist has a discrete developmental model construct. Yet, it is clear, that unifying elements of stage development model for cultural learning are evident based on work from theorists including Jean Piaget, Lev Vygotsky, David Kolb, Erik Erikson, Milton Bennett, Mitchell Hammer, and Jack Mezirow. Just as models in engineering have both strengths and weakness, so too do developmental models. Yet a prevailing model that informs intercultural development is Bennett's proposed Developmental Model of Intercultural Sensitivity (DMIS) (Bennett, 1986, 1993, 2005, 2011).

The developmental stages move from ethnocentric positions to ethnorelativistic positions. At the denial position cultural differences are not perceived. At the defense position cultural differences are perceived in stereotyped or polarized ways. At the minimization position cultural differences are experiences through the lens of one's own cultural worldview. At the acceptance position cultural difference is experienced as just one of a number of equally complex worldviews. At the adaption position cultural difference is experienced an appropriate alternative behavior in a different cultural context. And at the integration position the experience of the person is one which allows for movement in and out of cultural worldviews.

Developmental Model of Intercultural Sensitivity

Development of Intercultural Sensitivity

\section{Experience of difference}

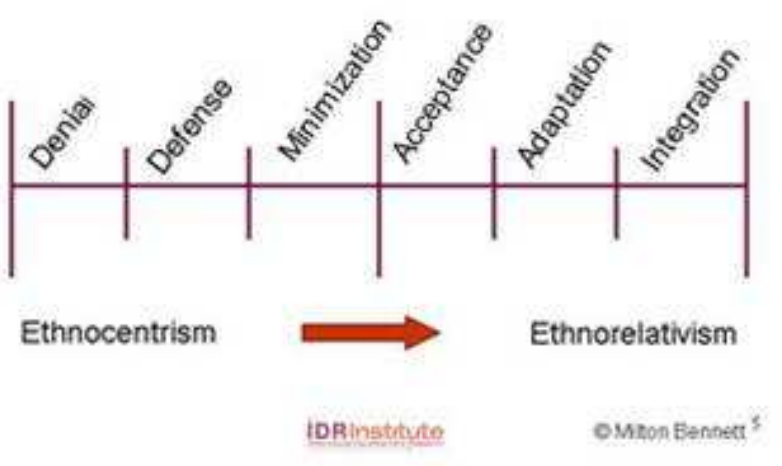

Copyright, Milton Bennett, Ph.D., used with permission

Outgrowths of the DMIS include the intercultural development continuum (IDC) and the Intercultural Development Inventory (IDI), a 50-item questionnaire. The IDI instrument has been rigorously tested and validated and is used by multiple disciplines and in multiple contexts by 
corporations, non-profit organizations, including health care organizations, and by higher education. The primary disadvantage of the IDI is the cost associated with the individual surveys and coaching which accompanies the survey instrument. While one of the researchers participated in IDI testing and mentoring, the cost was prohibitive for use of the instrument in this course. Other assessments considered included "Beliefs, Values \& Events Inventory (BEVI)", "Crosscultural Adaptability Index (CCAI)" and "Global Perspectives Inventory (GPI)"; these assessments also have cost constraints. Budget restraints therefore necessitated the use of free widely available cultural development instruments. Below, in the course case study description, these instruments are described.

\section{Literature Summary of Cultural Competence Needs of Engineers}

Clearly, the need for trained faculty to provide intercultural coaching in study abroad programs has been made. Most important to this study, is the need for intervention in instructor-led shortterm study abroad programs. Anderson et al (2016) have demonstrated that positive student intercultural gains can be made in short-term study abroad courses. Concerning is the intercultural knowledge regression that students experience in short-term programs where intervention is not incorporated into the course construction. Without structured reflection students project stereotypes or simply disengage when confronted with cultural difference. How these general education lessons translate to engineering courses has been explored in the engineering education literature.

Paterson, Swan and Watkins (2016) most recently reported on intercultural awareness of engineering student cohorts as measured by the IDI. Several interesting trends were reported. For example, lower IDI averages were reported from undergraduate teaching oriented schools than from research oriented universities. Other findings included a tendency for engineering students with an intercultural mindset to be attracted to service-oriented international experiences. Additionally, the researcher's validated previous research which found that student cultural growth is limited by the cultural attainment of the faculty who are leading the course.

Guzek, Paterson and Archer (2012) used multiple assessment tools including qualitative analysis, the Readiness Indicator derived from the Miville-Guzman University-Diversity Scale (MGUDS) and IDI in their research on undergraduate and graduate international community engagement programs. The researchers report on the motivations of engineering student participants and find that most engineering students will benefit from intercultural competency training.

Shen, Jesiek and Chang (2011) employed the M-GUDS short form in their study. Their recommendations for engineering courses included faculty should be mindful in providing engineering students with experiences that develop cultural awareness as a launching point for participation in immersive long-term global experiences. Additionally, instructors should be mindful of the different levels of student cultural awareness in order to appropriately tune student activities. 
In a study conducted by Klein-Gardner and Walker (2011), several prominent engineers in industry and academia were surveyed to better understand what it means for an engineer to be globally competent. Their results found that the most important traits of a globally competent engineer are as follows: "1) the ability to communicate across cultures, 2) the ability to appreciate other cultures, 3) a proficiency working in or directing a team of ethnic and cultural diversity, 4) the ability to effectively deal with ethical issues arising from cultural or national differences, 5) possessing understanding of cultural differences relating to product design, manufacture, and use, and 6) possessing understanding of implications of cultural differences of how engineering tasks might be approached".

Pitts and McGonagle (2013) expand the conversation to consider the intersection of study abroad with leadership and communication skills. Pitts and McGonagle state, engineers should be "able to explain point of view, approach those with differing backgrounds and cultures; assess the extent to which you are understood... Appreciate, engage, and connect with those who have different perspectives." These researchers reported a 100\% greater improvement in GPA poststudy abroad. Students who studied abroad saw their GPAs rise twice as quickly as a result of going abroad.

Rising to the occasion of building a study abroad curriculum to engage students and ensure they are growing in their intercultural competence is a skill set rarely incorporated into engineering faculty's development. While designing engineering curriculum may have differences from curriculum designed for other fields, engineering education researchers have provided recommendations for curriculum construction. For example, "It is crucial to set expectations for academic and personal conduct as early as possible, and to emphasize that the pre-departure activities exist as the first element on the continuum of the program lifecycle," (Berger \& Bailey, 2013). Previous studies also suggest that students should engage in hands-on projects while abroad: "Regarding what and how students learn from their international experiences shows the practical benefits for students of implementing 'real projects' ... These experiences make an impression that is hard to replicate in a traditional classroom setting," (Korte et al, 2011). No two study abroad programs are exactly alike, but these shared recommendations and lessons learned may be moving the needle for student intercultural growth.

\section{Course Case Study}

The University of St. Thomas, School of Engineering has consistently offered engineering study abroad coursework. Many of these courses are led by faculty in the compressed January semester which is otherwise known as J-term. A high participation rate in the study abroad J-term courses has been attributed to the need for the credits, the enticing study away locations and the unique engineering content offered in these intense formats. In odd numbered years, this course, ENGR 271 Roman Structures, Engineering \& Society, has been directed by two veteran adjunct faculty members. Previously, the course construction has followed a traditional teaching philosophy. In 2017, the previous content continued to be presented in the same manner, including site visits to historical structures in Italy, presentations on the history of the architecture and catholic social 
justice content. Additionally, the areas visited continued to be in Rome, Pompei, Naples, Florence, Sienna, San Gimignano, Modena, Pisa, Carrara, and Florence.

The new variable in 2017 was constructivist-oriented instruction focused on two new streams of course content: 1 . Transfer of engineering mechanics knowledge, specifically statics and strength of materials, to structural analysis of historical structures and 2. Intercultural learning using focused activities, critical reflection and intentionally structured modules. New course components began with pre-departure small group presentation assignments. These course components conformed to inclusive instruction practices as reported by Winkelmes et al. (2016) for transparency in learning and teaching in higher education. Two new assignments required students to work in pre-assigned groups of three and four students. Students were randomly assigned to two discrete groups with the goal of creating interwoven groups who would be collaborating and building professional student working relationships before departure. The structure of both assignments also allowed for a jigsaw approach (Johnson \& Johnson, 2006) to covering content. Students were required to take a deep dive into focused aspects of the course with the requirement that they teach, in reality orient, their peers to the content that they were "experts" in. In return, each student was dependent on peers for other aspects of course content.

The first pre-departure assignment set the course direction for the engineering knowledge transfer. The assignment entitled "Engineering in Roman Structures" consisted of eight small group presentations. Verbally and through written directions, it was conveyed that the purpose of the assignment was for students to transfer basic engineering knowledge to the structures to be visited. Specific components to be focused upon were the engineering mechanics and materials content previously encountered. Engineering topics were correlated with site visits including Rome's Capitol Hill, Trajan Column, Vatican architecture, Roman aqueducts, Brunelleschi's Santa Maria del Fiore dome, etc. Required reading and reference for this content included Bill Addis" "Building: 3000 Years of Design Engineering and Construction" (Addis, 2008). This assignment allowed for students to engage with the engineering content before departure. Additionally, this assignment allowed for students to engage in small group teamwork. Assessment was based on AAC\&U's "Inquiry and Analysis" and "Teamwork" VALUE rubrics (Rhodes \& Finley, 2014).

The second pre-departure small group assignment set the baseline course direction for intercultural learning. The assignment, entitled "Regional Cultural Presentations", oriented students toward the objective cultural components of regions visited. This assignment identified how the objective cultural components, or products, including art, music, architecture and literature, were differentiated from subjective cultural components. This assignment served as the anticipatory set for differentiating between objective and subjective culture. Small groups investigated Rome, Pompei, Naples, Florence, Sienna, San Gimignano, Modena and Pisa. Assessment was based on AAC\&U's "Teamwork" and "Intercultural Knowledge" VALUE rubrics.

Given the importance of instructor intervention in cultural learning development, numerous interventions were prepared in anticipation of a wide variety of anticipated needs. Intercultural learning content drew from several sources including the Institute for Cross-Cultural Teaching and Learning and publications from Stringer \& Cassidy (2003, 2009) and Hofstede (2012). 
Attention to balancing student learning support with student challenges was considered when considering appropriate points of intervention. Ideally, interventions move student learning from the comfort zone, where knowledge and skills are established, to the learning zone, where students' curiosity is peaked and self-motivation is highest (Harvey, 2013).

Intercultural learning began in the pre-departure meeting with an interactive name learning activity, an introduction of the pre-departure small group work, and a proxemics activity. The proxemics activity required students to take on a behavior unbeknownst to the other students and then interact in conversation about the upcoming travel away. Examples of these characteristics, which in some cultures indicate appropriate behavior, including: avoiding eye contact; actively listening by shaking head in agreement; ensuring personal space by standing more than 18 inches away; listening without fidgeting; speaking quickly without the use of vocalized fillers such as "um"; listening without interrupting; standing in an upright, stiffened posture with arms firmly folded in front of you; and maintaining a serious face without the use of smiles. When the conversation partner did not mimic these behaviors, the assigned person shared a toothpick with the conversation partner. Students were instructed to converse with others, and then at regular intervals students were redirected to another person for a new conversation. In the debrief of the activity students shared reflections that indicated a level of discomfort of receiving a toothpick without understanding exactly what their offending behavior may have been. Students also shared that they did not want to offend others simply because they did not understand cultural norms. This in turn led to a discussion on what they might do or be open to observing through the study away experience.

Varied intercultural processing lessons were employed across the study abroad short session. The first lesson included students being instructed on how they were to begin their daily journal. Students were instructed to begin by clearly describing their experiences as they experienced the new environment through their senses. This guided session required students to close their eyes and intentionally consider what they had experienced through their sight then after a quiet reflection period they were asked to consider what they had experienced through hearing. This pattern continued through touch, smell and taste. Successive sessions built off the first session by having students build off by the clear sensory description phases by walking through the describe/interpret/evaluate exercise. The describe-interpret-evaluate model, which sets a structure for students segmenting these steps, was employed as a tool for deeper processing of experiences through a slightly shifted lens (Paige, 2006). This technique requires students to slow down their interpretation and evaluation of a situation and pose alternative interpretations of a situation along a spectrum positive and negative interpretations. Another intercultural processing tool employed was the "Visual Speaks" exercise which relies upon vetted pictures as a starting point for discussion. At the beginning of the study abroad experience students were asked to pick a picture which represents their experience in the new culture and articulate what they were experiencing. Visual Speaks modules were used as a tool for identifying and articulating emotional content of the intercultural experience.

Variation in intercultural modules continued throughout the short course. A "post-it-note" module relied upon students writing out three intercultural learning goals at the beginning of the short course experience on post-it-notes. Students then posted their goals in like-minded groups 
upon the wall. These post-it-notes required students to "anonymously" identify their own goals as they also understood and acknowledged others' goals. This module was used again at the end of the study abroad experience with a result of students' goals growing in sophistication. An "objective-subjective" module had students identify where upon the continuum of objective and subjective cultural experiences specific experiences could be pinned. In processing this content, otherwise unshared experiences surfaced and were articulated in a way that peers could also then translate their own experiences into.

The "zone of learning" module required students to work in pairs and discuss experiences that stood outside of their daily experience. By articulating these experiences, for example one student had been yelled at in another language, they were better able to provide one another with a yet unexplored explanation of what may have underlie the experience. Students were instructed to find someone who they had not spoken with extensively through the study abroad experience; thus, they had another person who had not experienced the situation with them provide alternative explanations of what they had experienced. The "intercultural knowledge selfassessment" module had students working in self-selected pairs to self-identify were they fell within the AAC\&U VALUE Intercultural Knowledge and Competence rubric. These pairs had students working with students with whom they had a natural affinity to facilitate safe disclosure of their self-assessment. Yet another module had students self-evaluate where they lie on Milton Bennett's Development of Intercultural Sensitivity. Although this instrument is not designed for self-evaluation this method allowed to students to better understand the ethnocentric to ethnorelative spectrum as they set their own personal growth goals. The "professional debriefing" module had students construct one-minute elevator speeches for a professional i.e., interview, experience as well as an informal bullet point list that addressed the question "What did you do and what did you learn?". This module allowed for a deeper conversation on the role that intercultural competence will play in their engineering career, as well as goals that employers are setting for engineering applicants, employees and managers.

These modules were prepared to facilitate student discussion and were used strategically to further conversations that were happening at that point in the study abroad experience. Examples of conversations which arose organically included a discussion on the difference in the golden rule, "treat others as you would want to be treated", and the platinum rule, "treat others as they would want to be treated". This discussion allowed for a deeper exploration of how an average college student from their university might want to be treated differently than someone in the study abroad country.

Clearly the role of reflection was central to student growth. This occurred in a structured format through individual reflection, small group processing and large group processing. Deeper individual reflection was incorporated into individual student reflection journals. The deep dive into student reflection is forthcoming. Yet preliminary analysis of student intercultural learning holds some interesting findings. 


\section{Research Study and Findings}

The research approach taken to measure student cultural learning is a mixed methods research structure with a nod to quantitative cultural competence measures and a forthcoming qualitative hermeneutic phenomenology delve into understanding the experience. The research question explored and reported upon is "To what extent may a short-term study abroad engineering course influence student intercultural competence?"

The quantitative cultural competence measures are based on the American Association of Colleges and Universities (AAC\&U) VALUE rubrics of "Intercultural Knowledge and Competence" and "Global Learning". Surveys were constructed based on Dr. Charles Calahan's "short scales" of the AAC\&U "Intercultural Knowledge and Competence" and "Global Learning" rubrics. Additionally, students were asked to self-assess their rating on the actual AAC\&U rubrics. Students were invited to complete the survey before and after departure. Those students who did not complete the survey before departure, were invited to complete the survey post study abroad experience from where they were before the experience to where they were after the study abroad experience.

In addition to student self-reports on intercultural knowledge and global learning, interviews were conducted with students after the conclusion of the course. Interviews were semi-structured with questions focused on students sharing the experience of intercultural growth. Students were asked to recount and interpret specific experiences of intercultural growth. Phenomenological hermeneutic analysis is underway with discussion to be provided at a future date.

The students' responses on the pre-trip survey indicate not only a strong desire to learn about different cultures, but also an awareness of a lack of intercultural competence in their lives. For example, one student states, "I hope that this experience continues to expand my horizons and help[s] me develop a better worldview." Another student states, "I like to think that I am proficient at nonverbal communication, but I now realize that I have only been exposed to nonverbals in my particular corner of the world." The pre-survey results included students identifying that $60 \%$ of the respondents self-report they don't ask questions about other cultures, and a very small percentage said they ask questions and try to seek answers. Pre-survey respondents also identified that $45 \%$ of the students self-report they don't understand cultural differences in nonverbal and verbal communication, and 50\% are not able to use a worldview different from their own to interpret views/actions of other cultures. These data points suggest students are not only underperforming in matters of intercultural competence, but are also aware of their own shortcomings in this area.

Several students express their hopes the program will provide them with a meaningful cultural experience when they shared, "I would like to try and get a better understanding of the culture differences between Italy and the United States," "My goal in Italy is to try to immerse myself in the culture," and "A goal of mine would be to take time to notice how things function in a different society." These students are acutely aware of the benefits they expect from a sojourn abroad, and they were also aware of ways in which an experience abroad can benefit their engineering careers. One student stated, "As an engineer, I feel obligated to be looking and 
trying to find practical solutions to global challenges more from a mechanical perspective," while another stated, "Not understanding your own culture and not attempting to understand others' can harbor hostility and create barriers between people of all backgrounds."

\begin{tabular}{|c|c|c|}
\hline To what degree do you welcome interactions with person culturally different from you? \\
\hline Pre-survey
\end{tabular}

Figure 1: Pre-trip and post-trip measure of welcome interactions with person culturally different

\begin{tabular}{|c|c|c|}
\hline \multicolumn{3}{|c|}{$\begin{array}{c}\text { To what degree do you ask questions, plus seek the answers to these questions, about other } \\
\text { cultures regarding cultural differences? }\end{array}$} \\
\hline Pre-survey & Post-survey & Key \\
\hline $23.8 \%$ & & $\begin{array}{l}\text { Not At All: You are not aware of or do } \\
\text { not recognize this behavior. } \\
\text { Low Degree: You are only aware of } \\
\text { and recognize this behavior. } \\
\text { Somewhat Low Degree: You cooperate } \\
\text { or comply with this behavior if requir... } \\
\text { Somewhat High Degree: You } \\
\text { recognize the value of and prefer thi... } \\
\text { High Degree: This behavior is an im... } \\
\text { Very High Degree: This behavior is } n . . .\end{array}$ \\
\hline
\end{tabular}

Figure 2: Pre-trip and post-trip measure of questioning and answer seeking about culturally differences 


\begin{tabular}{|c|c|c|}
\hline $\begin{array}{c}\text { To what degree are you able to use a worldview different from your own to interpret the views } \\
\text { or actions of person from other cultures? }\end{array}$ \\
\hline Pre-survey & \multicolumn{1}{|c|}{ Post-survey } & Key \\
\hline $19 \%$ & $\begin{array}{l}\text { Not At All: You are not aware of or do } \\
\text { not recognize this behavior. } \\
\text { Low Degree: You are only aware of } \\
\text { and recognize this behavior. } \\
\text { Somewhat Low Degree: You cooperate } \\
\text { or comply with this behavior if requir... } \\
\text { Somewhat High Degree: You } \\
\text { recognize the value of and prefer thi... } \\
\text { High Degree: This behavior is an im... } \\
\text { Very High Degree: This behavior is } n . . .\end{array}$ \\
\hline
\end{tabular}

Figure 3: Pre-trip and post-trip measure of ability to use a different worldview and interpret views from other cultures

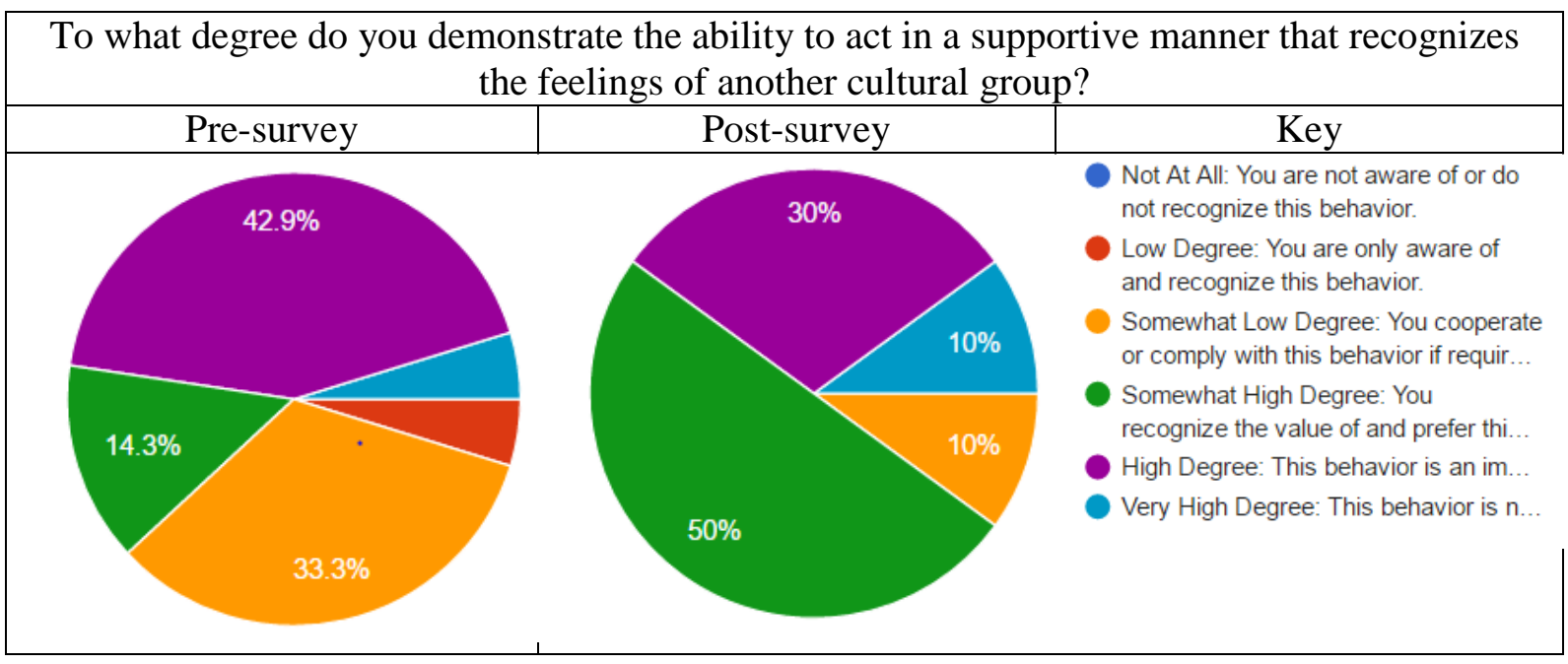

Figure 4: Pre-trip and post-trip measure of ability to demonstrate the ability to act in a support manner that recognizes the feelings of another cultural group?

When reviewing the students' responses on the post-trip survey, it was noted the students selfreported gains in cultural competence in every area about which they were questioned. Side by side comparisons of student self-beliefs show relative growth as demonstrated by Figures 1 through 4. Students rated themselves as not only improving in all areas of interest, but also improving relatively equally across the board. The students rated themselves as improving by $3 \%$ in the attitude, skills, and knowledge of cultural competence section, improving by $8 \%$ in the 
global learning section, and improving by $7 \%$ in the intercultural competence and knowledge section. While these percentages of self-reported improvement are not exceptionally high numbers, they are consistent and show a definite increase in the students self-report of cultural competence. Given previous findings of student regression in short-term study abroad, there appears to be a positive springboard for future course construction.

\section{Discussion \& Next Steps}

While this study is preliminary, there is some evidence which supports Anderson, Lorenz and White's (2016) findings that student intercultural gains are possible in a short course. Our data provides evidence that student intercultural gains were made over the course of a short-term study aboard course. While the data demonstrated modest gains in improvement, it is evident in the students' self-assessment survey answers that, an amount of cultural competence was gained. The self-assessment and intercultural-growth goals that students explored allowed these learners to set professional goals related to intercultural knowledge. As employers increasing employ intercultural knowledge assessment tools, including the IDI, for applicant and employee assessment, these students have begun to consider how their affinities and goals best match employer intercultural competence goals. Additionally, these students considered how user needs in engineering design may vary in terms of intercultural components.

The next steps in our process of exploring student growth in intercultural knowledge will include the next layer of data analysis. For this preliminary analysis, data was reviewed with a wide lens and averages were used to gain information from the students' survey answers. Future analysis will separate individual student answers and each question on the survey. Furthermore, semistructured interviews will be conducted with course participants to gain a deeper understanding of how students understood their experience from an intercultural growth perspective. These interviews will provide a nuanced understanding of the experience and the meaning that students attribute to their intercultural knowledge and competence. Clearly, one major limitation of this study is the lack of funding for a validated cultural assessment instrument. For future offerings of this course, additional funding will be sought for a validated assessment instrument as a means of better understanding these groups of students in relation to broader cohorts.

\section{References}

ABET. (2014). Criteria for accrediting engineering programs.

Addis, B. (2008). Building (Repr. ed.). London [u.a.]: Phaidon Press.

American Society of Civil Engineers. (2008). Civil engineering body of knowledge for the 21st century (Second Edition ed.). Reston, VA: American Society of Civil Engineers. doi:10.1061/9780784409657

Anderson, C. L., Lorenz, K., \& White, M. (2016). Instructor influence on student intercultural learning during instructor-led, short-term study abroad. Frontiers: The Interdisciplinary 
Journal of Study Abroad, XXVIII, 1-23. Retrieved

from http://search.proquest.com/docview/1816207112

Bennett, M. J. (2013). Basic concepts of intercultural communication : Paradigms, principles, and practices (2nd ed. ed.). New York: Intercultural Press. Retrieved from http://replaceme/ebraryid $=10960842$

Bennett, M. J. (rev 2011). A developmental model of Intercultural Sensitivity. Retrieved from IDR Institute website http://www.idrinstitute.org (pdf)

Bennett, M. J. (2005). Paradigmatic assumption of intercultural communication. Retrieved from IDR Institute website hhtp://www.idrinstitute.org (pdf)

Bennett, J. M. (2008). "Transformative training: Designing programs for culture learning." In M. A. Moodian (Ed.), Contemporary leadership and intercultural competence:

Understanding and utilizing cultural diversity to build successful organizations (pp. 95110). Thousand Oaks, CA: Sage.)

Bennett, M. J. (1993). Towards a developmental model of intercultural sensitivity in R. M. Paige, ed. Education for the Intercultural Experience. Yarmounth, ME: Intercultural Press.

Bennett, M. J. (1986). A developmental approach to training for intercultural sensitivity. International Journal of Intercultural Relations, 10(2), 179-196. doi:10.1016/0147-1767(86)90005-2.

Berger, E., \& Bailey, R. (2013). Designing Short-Term Study Abroad Engineering Experiences to Achieve Global Competencies, ASEE Annual Conference, Atlanta, Georgia, June 2013.

Berger, P. L., \& Luckmann, T. (2011). The social construction of reality: A treatise in the sociology of knowledge. Newburyport: Open Road Media.

Guzek., K. L., Paterson, K. \& Archer, A. (2012). A Comparative Assessment of Graduate Versus Undergraduate Outcomes via International Community Engagement Programs, ASEE Annual Conference, San Antonio, TX, June 2012.

Hammer, M.R. (2008). The Intercultural Development Inventory (IDI): An Approach for assessing and building intercultural competence. In M.A. Moodian (Ed.), Contemporary leadership and intercultural competence: Understanding and utilizing cultural diversity to build successful organizations. Thousand Oaks, CA: Sage

Hammer, M. R., Bennett, M. J., \& Wiseman, R. (2003). Measuring intercultural sensitivity: The intercultural development inventory. International Journal of Intercultural Relations, 27(4), 421-443. doi:10.1016/S0147-1767(03)00032-4 
Harvey, T. A. (2013). Facilitating intercultural development during study abroad: A case study of CIEE's seminar on living and learning abroad Available from ProQuest Dissertations and Theses Professional. Retrieved from http://www.riss.kr/pdu/ddodLink.do?id=T13398081

Hofstede, G. J., Pedersen, P. B., \& Hofstede, G. (2012). Exploring culture (Nachdr. ed.). Boston [u.a.]: Intercultural Press.

Institute of International Education (IIE) \& U.S. Department of State's Bureau of Educational and Cultural Affairs.2016 open doors report on international educational exchange executive summary. Retrieved from http://www.iie.org/Who-We-Are/News-andEvents/Press-Center/Press-Releases/2016/2016-11-14-Open-Doors-ExecutiveSummary\#.WE8ineYrJPY

Johnson, D. W., \& Johnson, F. P. (2006). Joining together (9. ed. ed.). Boston [u.a.]: Pearson.

Jovanovic, V., DeAgostino, T.H., Thomas, M.B., \& Thomas Trusty II, R. (2012). Educating Engineering Students to Succeed in a Global Workplace, ASEE Annual Conference, San Antonio, Texas, June 2012.

Kitsantas, A. (2004). Studying Abroad: The Role of College Students' Goals on the Development of Cross-Cultural Skills and Global Understanding. College Student Journal, 38(3), 441452.

Klein-Gardner, S.S., \& Walker, A. (2011). Defining Global Competence for Engineering Students, ASEE Annual Conference, Vancouver, Canada, June 2011.

Korte, R., Elliott-Litchfield, B., Hahn, L. D., Lewicki, A. D., Werpetinski, V., \& Won Hong, S. (2011). A participatory investigation of learning in international service projects, ASEE Annual Conference, Vancouver, Canada, June 2013.

Moodian, M. A. (2009). Contemporary leadership and intercultural competence. Los Angeles, Calif. [u.a.]: SAGE.

NAFSA: Association of International Educators. Trends in U.S. study abroad. Retrieved from http://www.nafsa.org/Policy and Advocacy/Policy Resources/Policy Trends and Data/ Trends_in_U_S_Study_Abroad/.

Paige, R. M. (2006). Maximizing study abroad (2. ed., 2. pr. ed.). Minneapolis, Minn: Univ. of Minnesota.

Paterson, K. Swan, C \& Watkins, D.W. (2016). Going is Not Knowing, ASEE Annual Conference, New Orleans, LA, June 2016.

Pitts, S., \& McGonagle, S. (2013). Developing Engineering Leaders using Engineering Leadership Capabilities and Leadership Labs, ASEE Annual Conference, Atlanta, Georgia, June 2013. 
Rhodes, T., \& Finley, A. (2014). Using the VALUE rubrics for improvement of learning and authentic assessment. Peer Review, 16(3), 32

Shen, Y., Jesiek, B. K. \& Chang, Y. (2011). Cultural Orientation and Global Competency, ASEE Annual Conference, Vancouver, Canada, June 2011.

Stringer, D. M., \& Cassidy, P. A. (2003). 52 activities for exploring values differences (1. publ. ed.). Yarmouth, Me: Intercultural Press.

Stringer, D. M. \& Cassidy, P. A. (2009). 52 activities for improving cross-cultural communication. GB: Nicholas Brealey Publishing.

Vande Berg, M., Paige, R. M., \& Lou, K. H. (2012). Student learning abroad: What our students are learning, what they're not, and what we can do about it. Sterling: Stylus Publishing.

Winkelmes, M., Bernacki, M., Butler, J., Zochowski, M., Golanics, J., \& Weavil, K. H. (2016a). A teaching intervention that increases underserved college students' success. Peer Review, 18(1-2), 31. Retrieved from http://search.proquest.com/docview/1805184428 